\title{
Detection of Rare Earth Elements in Appalachian Coal Fly Ash by Cathodoluminescence Spectroscopy
}

\author{
Amy Falcon ${ }^{1}$, James A. Poston $\mathrm{Jr}^{2 *}$ Scott Montross $^{3}$ and Circe Verba ${ }^{4}$ \\ 1. Oak Ridge Institute for Science Education (ORISE), Department of Energy, National Energy \\ Technology Laboratory, Morgantown, WV, USA. \\ 2. Department of Energy, National Energy Technology Laboratory, Morgantown, WV. USA. \\ 3. Leidos Research Support Team, National Energy Technology Laboratory, Albany, OR. USA. \\ 4. Department of Energy, National Energy Technology Laboratory, Albany, OR. USA. \\ * Corresponding author: James.Poston@netl.doe.gov
}

Cathodoluminescence (CL), the excitation of an inorganic material by energetic electrons that results in photon emission, is one of several mechanisms that occurs as a result of the interaction of an electron beam with an inorganic solid. Photons are emitted as the result of electronic transitions between the conduction and valance bands as well as levels lying with the band gap and can be characterized as being intrinsic (fundamental) or extrinsic (activated). Rare Earth Elements are an extrinsic source that can be detected using CL, with the CL signal being sensitive to the chemical state of the polyvalent elements [1, 2]. CL microscopy and spectroscopy and X-ray Microanalysis/Energy Dispersive Spectroscopy (XRM/EDS) was initiated on a series of coal fly-ash samples collected from the Appalachia region to ascertain the location(s), type(s), and valance states of REE's in the fly-ash samples. XRM/EDS and CL microscopy and spectroscopy was carried out utilizing a Thermo-Electron NS-7 and a Gatan Mono-CL4 interfaced to a JEOL-7600 FESEM. The Gatan CL system is equipped with a PMT and a Princeton Instruments PIXILS 100 CCD camera. Primary analyses were carried out in a wavelength range of approximately $300 \mathrm{~nm}$ to $750 \mathrm{~nm}$.

The CL spectroscopic data acquired from the fly-ash samples was compared to the cathodoluminescence spectra obtained from various mineral standards as well as the CSIRO Luminescence Database [3]. EDS was used to identify the host environment as well as REE's such as lanthanum $\left(\mathrm{La}^{3+}\right)$ and lutetium $\left(\mathrm{Lu}^{3+}\right)$ that exhibit non-distinctive broad band emissions and whose photon emission wavelengths are outside of the experimentally detectable wavelengths. Of the 17 rare earth elements, 12 were detected in coal fly ash samples by CL, while La was detected by EDS. The REE's identified in the fly-ash samples by CL (Figure 1) were primarily associated with minerals while La which was detected by BSEI and EDS, was associated with clay. The data in Table 1 depicts the cumulative observed spectral lines for each REE according to the type of mineral in which each REE is retained. The observed CL wavelengths correlate well with CSIRO database and mineral standards, indicating that the combustion process and weathering have negligible effect on the REE location, type, and valance state.

\section{References:}

[1] JI Goldstein et al., in "Scanning Electron Microscopy and X-ray Microanalysis", (Springer).

[2] BG Yacobi and DB Holt in "Cathodoluminescence Microscopy of Inorganic Solids", (Springer

Science \& Business Media).

[3] Commonwealth Scientific and Industrial Research Organization (CSIRO) Luminescence Database, www.csiro.au/luminescence (accessed January 31, 2019). 
a)

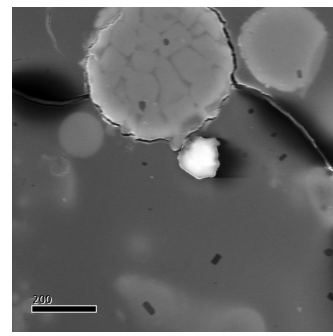

b)

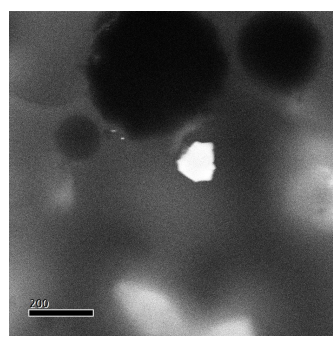

c)

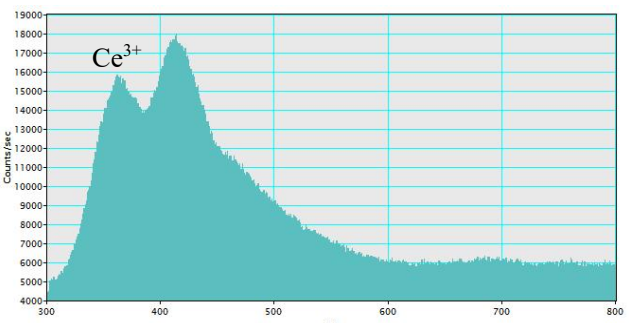

Figure 1. a) SEI; b) CL Image; c) CL spectrum of $\mathrm{Ce}^{3+}$ in calcite

\begin{tabular}{|c|c|c|c|}
\hline Mineral & Activator & Observed Peak & CSIRO Database Peak [3] \\
\hline Alumina & $\mathrm{Eu}^{3+}$ & 617,690 & 614,692 \\
\hline \multirow[t]{2}{*}{ Anhydrite } & $\mathrm{Sm}^{3+}$ & 637,730 & 640,732 \\
\hline & $\mathrm{Tb}^{3+}$ & 438 & 436 \\
\hline \multirow[t]{7}{*}{ Apatite } & $\mathrm{Ce}^{3+}$ & $361,457,458$ & 360,458 \\
\hline & $\mathrm{Dy}^{3+}$ & $576,579,580,667$ & $575,577,578,580,667$ \\
\hline & $\mathrm{Eu}^{2+}$ & 410,448 & 410,450 \\
\hline & $\mathrm{Eu}^{3+}$ & 690,695 & 690,695 \\
\hline & $\mathrm{Sm}^{3+}$ & 654,690 & 654,690 \\
\hline & $\mathrm{Tb}^{3+}$ & $413,434,487$ & $414,436,487$ \\
\hline & $\mathrm{Tm}^{3+}$ & 361 & 363 \\
\hline \multirow[t]{2}{*}{ Barite } & $\mathrm{Ce}^{3+}$ & 330,333 & 330 \\
\hline & $\mathrm{Eu}^{2+}$ & $372,374,375$ & 375 \\
\hline Calcite & $\mathrm{Ce}^{3+}$ & 356 & 357 \\
\hline Dolomite & $\mathrm{Ce}^{3+}$ & 362 & 362 \\
\hline \multirow{3}{*}{ Feldspar } & $\mathrm{Ce}^{3+}$ & 335 & 335 \\
\hline & $\mathrm{Er}^{3+}$ & 535 & 532 \\
\hline & $\mathrm{Tb}^{3+}$ & 550 & 550 \\
\hline \begin{tabular}{|c|} 
Lanthanum \\
monophosphate
\end{tabular} & $\mathrm{Eu}^{3+}$ & 693 & 692 \\
\hline \multirow[t]{4}{*}{ Xenotime $(\mathrm{Y})$} & $\mathrm{Er}^{3+}$ & 518,525 & $520,525,526$ \\
\hline & $\mathrm{Dy}^{3+}$ & $660,663,743,745$ & $651-669,735-771$ \\
\hline & $\mathrm{Ho}^{3+}$ & $546,660,743,745$ & $546,659,742,743$ \\
\hline & $\mathrm{Nd}^{3+}$ & 663 & $656-670$ \\
\hline \multirow{8}{*}{ Zircon } & $\mathrm{Dy}^{3+}$ & $472,474,475,484,487,578,665,758$ & $472,483,485,486,578,665,755$ \\
\hline & $\mathrm{Er}^{3+}$ & $402,403,406,408,528,532,546,620$ & $405,530,545,548,620$ \\
\hline & $\mathrm{Eu}^{3+}$ & 578,638 & 575,635 \\
\hline & $\mathrm{Ho}^{3+}$ & $532,538,540,670$ & $530,539,660-670$ \\
\hline & $\operatorname{Pr}^{3+}$ & $528,532,546,620,745$ & $530,544,620,742$ \\
\hline & $\mathrm{Sm}^{3+}$ & 578 & 575 \\
\hline & $\mathrm{Tb}^{3+}$ & $417,546,587,625$ & $417,546,590,625$ \\
\hline & $\mathrm{Tm}^{3+}$ & 458,758 & 457,755 \\
\hline
\end{tabular}

Table 1. Minerals and rare earth activators found in coal fly ash, as determined by cathodoluminescence spectroscopy. 